\title{
The Social Consequences of Raising Medically Fragile and Developmentally Challenged Children in Ghana
}

\author{
Robert B. Kuganab Lem \\ Dept. of Allied Health Sciences \\ University for Development Studies \\ Tamale, Ghana \\ Email: Kuga_robert@hotmail.com \\ DOI: http://dx.doi.org/10.4314/gjds.v8i2.3
}

\begin{abstract}
Various challenges and stresses affect families raising children who are medically fragile or developmentally-challenged. This paper explores the social consequences of raising children who are medically fragile and/or developmentally challenged. It is an ethnographic study of 13 families within the Tamale Metropolis. The overarching theme was the families' search for safety and comfort doing their daily chores and in social situations. Major issues they have to deal with included overcoming environmental challenges and attitudinal barriers. Where safety and comfort could not be achieved, families were likely to limit social activities so that the child who was medically fragile and or developmentally challenged could be cared for at home, a secured environment in the view of parents.
\end{abstract}

Keywords: Social Situation; Medically Fragile Child; Developmentally Challenged; Chronically Ill Child, Disability.

\section{Introduction}

The 1992 Constitution of Ghana guarantees the right of disabled people to special treatment. Section 59 of the Persons With Disability Act, 2006 (Act 715) defines a person with disability as an "individual with a physical, mental or sensory impairment including a visual, hearing or speech functional disability which gives rise to physical, cultural or social barriers that substantially limit one or more of the major life activities of that individual." UNICEF (2008), in a survey of children aged two to nine years, reports that in Ghana $13 \%$ of children in this age group have at least one disability as reported by their mothers or care givers.

Children who are disabled or medically fragile often need to be monitored and assisted by others to ensure that they receive needed care because their developmental disabilities 
may prevent them from attaining independence in caring for themselves. The complexity and continuous nature of the conditions of medically fragile children and the high level of skills their care demands, differentiates children who are medically fragile and developmentally challenged from the general population of children (Harrigan, 2002; Kirk, 1998). The complex and continuous care that such children need put extra stress on parents, especially mothers, thus limiting their participation in social activities. Medically fragile children require skilled and supportive care to survive and partake in daily life. Their families and friends have the added responsibility to providing not just care but specialized and extra care, physically, emotionally and socially, as such children are not able to function adequately at their age level. Care for such children might be a life-time matter constraining the families, in particular. Yet, little research has been done in Ghana on the social consequences of managing such care for families raising such challenged children. It is important for policy makers to understand the situation of such parents so as to support their care activities and provide for their social needs.

Published critical reviews on various aspects of family care for children in Europe conclude that families are emotionally, physically, and financially stressed, often anxious about their child's condition or the complications that may develop and fearful of potential emergency situations that may occur (Hastings \& Taunt, 2002; Harrigan, et al., 2002). For instance, Harrigan and associates (2002) found that families need extensive, continuous services, including education, emotional support, skilled supportive respite care and financial assistance to be able to care for their children and wards. They also recommend that much more research is needed to clarify how health care providers and governmental services can direct interventions and policies to best assist these families. Some reviewers point to positive experiences related to raising children who are medically fragile. These positive experiences include increased family closeness, personal growth and greater tolerance for human variations and respect for differences (Glidden \& Johnson, 1999; Hastings \& Taunt, 2002; Rehm, 2000; Sandler \& Mistretta, 1998; Scorgie \& Sobsey, 2000). Parents, and in some cases children, with chronic conditions have been widely described as mostly normal despite their special needs (Deatrick, Anafi, \& Murphy-Moore, 1999; Morse, Wilson, \& Penrod, 2000; Robinson 1993). What is the situation in Ghana? What can be done to mitigate the situation of such parents?

\section{Conceptual Issues}

Social consequences for families have no standard definition, but researchers have acknowledged the importance of social relationships and activities to a high quality of life. Poston, et. Al. (2003) examined the conceptualization of family quality of life based on perceptions of 187 individuals, who included children with disabilities and their family members, children and families without disabilities and, service providers. They developed a schema of family quality of life that placed social outcomes into two individually oriented domains, social well-being and productivity, which affected all members of the family. Social well-being included social acceptance, social relationships, 
and practical support. Productivity included the abilities to engage in enjoyable hobbies and to balance work and family life.

In this paper, the term social consequences is used to indicate outcomes relating to the ability of families to engage in relationships with people outside of close family and to participate in social events including naming ceremonies, funerals and weddings. Among factors leading to social consequences are difficulty in finding caregivers and the financial strains that medically fragile children impose on the family (Kirk\& Glendinning, 2004; O’Brien, 2001; Ratliffe et al., 2002; Wang \& Barnard, 2004). O’Brien (2001) used the term social isolation and related it to lack of time because of the demands of caregiving and a focus on intra-familial needs that impaired social relationships and opportunities for socialization with friends and family. Poston and associates (2003) also mention the discomfort of friends of family members regarding a child with disability. Additionally, Kirk and Glendinning (2004) identify the people's reactions to care procedures of the developmentally challenged as impediments to socialization.

Researchers relate the extent of social consequences from providing care to children with chronic conditions to the type of condition and the extent of care needed. Taanila, Jarvelin, and Kokkonen (1999) found that families raising children with diabetes experienced significantly less impact on family life, especially leisure activities, than families of children with disabilities. The authors related this difference to the constant care needed by the children with disabilities that decreased parents' time for themselves and to the ability of families caring for a child with diabetes to return to a fairly stable family routine. This is consistent with Poston and associates' (2003) finding that families caring for children with problem behavior or complex medical needs were often unable to leave their children or join in spontaneous social activities.

Taken together, available literature documents some of the factors influencing social consequences of raising a child with a serious chronic condition or one who is developmentally challenged. However none of these studies have highlighted the situation in Africa nor have they examined this topic in depth for a developing country. This study explores parents' perceptions of how their families' relationships with others and social activities were affected by raising children who were developmentally challenged and/or medically fragile.

\section{Design and Method}

This was an ethnographic study, based on a symbolic interaction framework. Researchers in this tradition focus on everyday life, gather data in natural field settings and recognize that knowledge is contextual, transactional and socially-derived (i.e., constructed by both researchers and participants whose understandings are influenced by their current situations, life experiences, interactions with others, and self-reflection) (Becker, 1998; Blumer, 1969; Fine, 1995; Prus, 1996.) 


\section{Procedures}

The study consisted of interviews with thirteen (13) mothers, five (5) fathers, one (1) custodial grandmother and four (4) children who were developmentally challenged. The focus of these interviews included the needs of the child, family responses to caring for challenged children, family activities, social lives of the family and child and, parental perceptions of normal family life.

Sampling was purposive. Children who were developmentally challenged were aged five to 12 years, eligible to attend school and had a variety of diagnoses including severe cerebral palsy, genetic conditions and injury because of trauma. The four children who were sufficiently verbal were interviewed, but most children were not articulate. The majority of the children needed assistance for mobility. Many had sensory deficits, particularly in hearing and speech.

Verbal assent for participation was obtained from the four children. This was feasible but difficult, requiring more time and effort. However, because most children were not verbal, parents provided consent on behalf of their children. Parents signed consent forms for their own participation.

Interviews with parents, mostly mothers, took place in the Tamale Teaching Hospital, the West Hospital, and the Tamale Central Hospital and also at family homes, at their convenience. The interviews were recorded and professionally translated and transcribed. Most of the interviews were conducted using Dagbani, the local language.

Sample size was determined by the principle of redundancy, also often called theoretical or data saturation (Lincoln \& Guba, 1985; Strauss, 1987). Participants were recruited until information gathered became redundant and, with new data fitting into identified categories and thus allowing in-depth consideration of each (Sandelowski, 1995).

\section{Data Analysis}

Data was analyzed using constant comparative techniques that allowed for tabulating and coding into various thematic categories. DeSantis and Ugarriza (2000) define a theme as "an abstract entity that brings meaning and identity to a recurrent experience and its variant manifestations. As such, a theme captures and unifies the nature or basis of the experience into a meaningful whole" (DeSantis, 2000: 362). Themes are developed by identifying and exploring major categories or dimensions in the data and discerning the major elements that tie them together. Thematic analysis requires that the researcher revisits the data systematically in order to contextualize and compare informants' perceptions, which might differ in some specifics, yet are united by the overall theme that expresses their common struggles or goals, and guides their actions in various situations.

All transcripts were coded using an open process (Strauss \& Corbin, 1998), and a summary of the family's story was written. The investigator, including students, participated in 
the data analysis. Each transcript was read by the investigator and a research assistant and a list of major categories was constructed by combining codes representing ideas, situations, actions and decisions that were recurrent across families. Then, analytic memos were written to facilitate discussion and stimulate consideration of multiple points of view in the interpretive process.

Rigor was insured by a variety of techniques common to qualitative methods. These included the use of multiple sources of data (e.g., family member interviews, home and hospital records.), methods of data collection (e.g., interviews and observations) and cross case analysis, in which information from each family was compared to each of the other families and similarities and differences in experiences and perceptions were explicitly sought. In addition, data analysis began soon after data collection and tentative findings were discussed with subsequent informants and interview guides were modified as necessary.

\section{Presentation of Findings}

Three major categories were reflected in data about the social consequences for families raising children who were medically fragile and/or developmentally challenged. These were anticipating and planning for the child's needs, dealing with barriers to social participation and finding or creating realms of social comfort for all members of the family and relations.

\section{Planning Needs of the child}

Although all of the focal children in the study were medically fragile and/or developmentally challenged, their individual care, preferences, and tolerances varied widely. Because some of the children were not ambulatory or verbal and could not care for themselves, parents were constantly vigilant for the child's safety and comfort and considered satisfying the child's needs as prerequisite to involvement in family social activities and situations. For example, basic physical care was a factor parents needed to take into account when planning visits or activities outside of the family home. Children all required assistance with routine types of activities of daily living such as feeding, dressing and freeing the bowels. Parents have to anticipate and plan, constantly, for both types of care whenever they were engaged in social activities.

One mother remarked about her daughter: "We live around her." Another said, "for us to do something little is so much different than what it takes a normal family if they had children of this age." Parents gave examples of differences such as needing several hours to get ready before leaving the house because children could not actively participate in their own care. Parents were also concerned about children's physical and emotional comfort, particularly in new situations. Many parents expressed frustration that children could not simply tell them what they needed or wanted at any given time. One mother said: "I want to hear her 
say, what she wants. I guess everything, if she's hungry, if she needs water, or she wants to go to the toilet... it would be nice for her to tell me: 'I' m hungry, I'm tired.'

The study revealed that majority of the children who were a little active enjoyed being around children outside of their own homes. However, because they could not defend themselves or complain, if threatened or had limited tolerance, parents were very aware of the need to monitor children's encounters. One observed: "I have to see what he is doing every minute or who he is playing or talking to. I can't leave her to be on her own with others for 5 minutes. There will be a problem."

Many children also had poor tolerance for the sun, heat, or cold weather especially during the Harmattan season. Hence, parents also had to monitor and protect their medically fragile children from the weather. One mother explained: "It's different. I can't just say ok go outside and play. I've got to worry about the rain or the wind. If rain touches him, he gets sick very quickly."

\section{Managing Barriers to Participation}

The study revealed the main barriers to social activities as environmental, child-related and/or attitudinal. Parents often found it easier when gatherings were in their own house. Where this is not the case, they simply stay at home as most of the children do not have wheelchairs to support their movement and could easily become the center of attraction at a social event even when that was not intended. The decision to stay at home meant that the challenged children were denied the opportunity to go out and meet with others. They basically were confined to one environment, particularly their own homes, for very long periods.

In addition to environmental barriers, social participation of families was often affected by children's developmental and behavioral differences and care needs. Children who were medically fragile or developmentally challenged often behaved in a manner that could be very embarrassing to family members or irritating to others. Loud vocalizations, hitting or kicking other children, drooling, seizures or incontinence of stool or urine could draw unwanted attention to the child and family. Parents were conscious of trying to be considerate of peoples' (i.e., non-family) feelings and sensibilities. The unpredictability of such behaviors and uncertainty about how people (i.e., outsiders) might react made parents cautious in new social situations. One explained: "She can just look at somebody and start crying loudly. She can ease herself and before you realize, she has it in her hands." Hence, the children's so-called unconventional or erratic public behaviors could affect their parent's ability to engage in social events and even force the mother especially to leave a situation so that the child would be comfortable or others would not feel disturbed.

Also, a families' ability to partake in social events was often affected by the negative attitudes of others, the 'outsiders.' A mother told a story about going to a funeral with the child as follows: "We were in a funeral house and this man turned around and looked, and said: 
'Why is she crying? Does she need water? She's handicapped and she's just crying because she's unhappy. Well, why do you bring her to a funeral.'“

Mothers sometimes became defiant, such as the woman described above; especially when they feel misunderstood or targeted for discrimination on the score of their children's condition. Parents also clearly differentiated between normal curiosity, particularly of other children, which they did not mind, and rude or discriminatory behavior, usually from adults. Most parents were also protective of children's feelings and longed for friends and relatives to treat all their children equally, even if the children themselves would be unaware of the slight.

\section{Creating Realms of Social Comfort}

A father was also philosophical, relating attending social events to the opportunity to educate society. According to him, giving everyone involved in the family a chance to participate in social activities in their own way and to make them feel loved and accepted and have a chance to make a contribution, matters in creating an environment in which the child is not neglected. He noted that participating in social events, a space consideration inappropriate for persons living with disabilities, helps break some of those stereotypes and the consequent boundaries imposed on the challenged child and even their parents and guardians.

It was generally noted that families often deliberately selected or modified their activities so that it was possible to include their child with special needs. That is going to places where there would be shade, sitting at the back of a church room to enhance the ability to leave if necessary. Nevertheless, despite their hopes and intentions, parents made frequent exceptions and ended up leaving the children who were medically fragile and/ or developmentally challenged at home at various times. The children left at home were usually cared for by a sibling, another relative in most cases a grandparent, or a maid servant. This became more common as the children got physically bigger and harder to carry and care for in public places.

Parents, especially mothers, expressed guilt and regret when they left their disabled child behind, and some parents were frustrated that the family could not be together for some social events. When asked to compare her family's activities to those of others raising normal children, one mother felt that her family's life was quite different. She said: “That's a big problem! We can't do anything together as a family. I mean, we can't go to church because we don't have a wheelchair for him. We can't go to any place else. Any place that we have to stay, we can't go." Another woman expressed how she felt guilty leaving her disabled child at home: "I always have a lot of guilt on me for leaving her at home because my daughter is a part of the family and it's not fair to isolate her. But she gets 24-hour attention, 7 days a week. And I know now that it's not wrong; you know, it's just like everybody gets a maidservant and they go out and do this and do that." 
Most parents were clear that they could only be friends with people who were accepting of their family's care giving needs and that, if relations and acquaintances were uncomfortable or treated their child differently from other children, they could not be friends. A mother explained, "We meet new people, make new friends, and if they don't like it, you know, oh well, they won't be your friend. If they can't accept our children as who they are, then they're not worth having as a friend."

Some parents made friends and became socially active with other families raising children with special needs. A father noted that "the people who work with these children or are parents of these children are some of the most wonderful people and our best friends have come from those families." However, other parents said that they did not know any others whose situations were similar to their own. None of the parents was active in formal parent support groups at the time of the study. Several families had found spiritual comfort and acceptance for their children and family at church, which also became a source of social encounters.

\section{Discussion of Findings}

The theme of searching for safety and comfort in social situations incorporates the ideas that satisfying the special care needs of the child who was medically fragile was a necessary starting point for all social activities, that many barriers to social participation existed. Social relationships and parents' social activities especially mothers are affected because of the intensity of needs and complexity of care required for the children who are medically fragile and developmentally retarded. Literature refers to this situation as social isolation (O'Brien, 2001; Wang \& Barnared, 2004) and most mothers described this feeling. "I am home all the time with him. Nobody helps me. I lost my sister's husband and I could not attend the funeral." Others who were able to attend some social events did recount many specific stresses and strains in such social events. These difficulties included obtaining respite and reactions of others to seeing the state of their children and care procedures.

For most of the parents, the search for safety and comfort in social situations was not always successful. Sometimes, care needs could not be satisfied. Some parents could not overcome the physical, child-related, or attitudinal barriers to social participation. When this occurred, families limited their social participation in some way, either choosing to stay home or socializing with a very limited group of relatives and in most cases leaving the child behind. All families had experienced some of these barriers to social participation though they reacted in varying ways. Some were resigned, some frustrated, and a very few defiant.

The study reveals that raising a child who is medically fragile or developmentally challenged affects families' social participation greatly. The theme of searching for safety and comfort in social situations describes the process by which parents calculate their ability to relax and enjoy themselves when participating in activities outside of their own homes and with people outside of their immediate family. Components of this theme 
included anticipating and planning for the child's care needs, overcoming environmental, child-related, and attitudinal barriers to social participation, and finding or creating realms of comfort.

\section{Limitations}

Sampling in this ethnographic study was purposive rather than statistically representational, thus findings cannot be said to be entirely generalizable. This study included educated and uneducated mothers, high income earners and low income earners but because the numbers were very small, the data was not segregated. Also, family social status can influence how people react to their developmentally challenged child. Individual experiences of mothers within these segments can provide additional information useful to enhance social participation.

\section{Clinical Implications}

Community Health Nurses who do home visits can assist families by helping them to anticipate and plan for the social consequences of raising their children with complex chronic conditions. The Social Welfare Department has a serious responsibility in providing resources to facilitate the participation of challenged children and families. The Social Welfare Department should assist parents to explore and develop a range of social and family activities that can include children with special needs. The provision of supplies and equipment to help in the care of such children is beyond most parents and government needs to intervene.

At the same time, parents can be reassured that it is possible for a child who is medically fragile or developmentally challenged to live a life that is fulfilling to her or himself and that society can also be helpful to ensure that such children achieve their potentials. Parents should also be encouraged to develop simple explanations for curious questions, especially questions from other children. They should also be assisted to develop assertive communication techniques that can enable them advocate for their children's rights and needs and yet facilitate the comfort of others and disarm negative or judgmental attitudes. 


\section{References}

Becker, H. S. (1998). Tricks of the trade: How to think about your research while you're doing it.

\section{Chicago: University of Chicago press.}

Blumer, H. (1969). Symbolic interactionism: perspective and method. Englewood Cliffs, NJ: Prentice-Hall.

Clarke-Steffen, L. (1997). Reconstructing reality: Family strategies for managing childhood cancer. “ Journal of Peadiatric Nursing," (12): 278-287.

Davidoff, A. J. (2004). "Identifying children with special health care needs in the National Health Interview Survey: A new resource for policy analysis”. Health Services Research, (39): 53-71.

Deatrick, J. A., Knaf, K.A., \& Murphy-Moore, C. (1999). Clarifying the concept of normalization. Image; “Journal of Nursing Scholarship",(31): 209-214.

DeSantis, L., and Ugarriza, D. N. (2000). The concept of themes as used in qualitative nursing research. "Western Journal of Nursing Research", (2):351-372.

Fine, G. A. (1995). A second Chicago school? The development of a postwar American sociology. Chicago: University of Chicago Press.

Glidden, I. M., \& Johnson, V.E. (1999). Twelve years later; Adjustment in families who adopted children with developmental disabilities. " Mental retardation”, (37): 16-24.

Harrigan, R. Ratliffe, C, Patrinos, M. E., Tse, A. (2002). Medically fragile children; An integrative review of the literature and recommendations for future research. "Issues in Comprehensive Pediatric Nursing", (25):1-20.

Kirk, S., \& Glendinning, C. (2004). Developing services to support parents caring for a technology-dependent child at home. "Child: Care, Health, \& Development". (30): 209-218.

Lincoln, Y., \& Guba, E. (1985). Naturalistic inquiry. Beverly Hills, CA: Sage.

Morse, J. M., Wilson, S. \& Penrod, J. (2000). Mothers and their disabled children: Refining the concept of normalization." Health Care for Women International", 21(8): 659-676.

O' Brien, M. (2001). Living in a house of cards: Family experiences with long -term childhood technology dependence. "Journal of pediatric nursing", 16(1): 13-22. 
Poston, D., Turnbull, A., Jiyeon, P., Mannan, H., Marquis, J., \& Wang, M. (2003). Family quality of life: A qualitative inquiry. "Mental Retardation", 41: 313-328.

Prus, R. (1996). Symbolic interaction and ethnographic research: Intersubjectivity and the study of human lived experience. Albany: state University of New York Press.

Rehm, R. S., Franck, L.. (2000). Normalization strategies and long term goals of children and families affected by HIV. "Advances in Nursing Science", 23(1): 69-82.

Robinson, C. A. (1993). Managing a life with a chronic condition: the story of normalization. "Qualitative Health Research", 3(1): 6-28.

Sandelowski, M. (1995). Focus on qualitative methods. Sample size in qualitative research. "Research in Nursing \& Health", 18 (2): 178-183.

Scorgie, K., Sobsey, D. (2000). Transformational outcomes associated with parenting children who have disabilities. "Mental Retardation", 38: 195-206.

Strauss, A. L. (1987). Qualitative analysis for social scientists. New York: Cambridge University Press.

Strauss, A. L., Corbin, J. (1980). Of qualitative research: Techniques and procedures for developing grounded theory ( $2^{\text {nd }}$ ed.). Newbury Park, CA: Sage.

Taanila, A., Jarvelin, M., \& Kokkonen, J. (1999). Cohesion and parents' social relations in families with a child with disability or chronic illness. "International Journal of Rehabilitation Research", 22: 101 - 109.

Trachtenberg, S.W. \& Batshaw, M.L. (1997). Caring and Coping: The family of a child with disabilities. In M.L. Batshaw (Ed.). Children with disabilities. $4^{\text {th }}$ Ed. (743-756). Baltimore, MD: Paul Brookes.

Wang, K.K., Barnard, A. (2004). Technology-dependent children and their families: A review. "Journal of Advanced Nursing," 45: 36-46. 